\title{
CARACTERIZAÇÃO E CONTROLE DE QUALIDADE DE VINAGRES COMER- CIALIZADOS NA REGIÃO METROPOLITANA DE CURITIBA/PR
}

\author{
CHARACTERIZATION AND QUALITY CONTROL OF VINEGAR MARKETED IN \\ METROPOLITAN REGION CURITIBA / PR
}

\author{
Rafaela Kropzak SCHMOELLER'; María Eugenia BALBI² \\ 1 - Aluna de Graduação do Curso de Farmácia \\ 2 - Professora da disciplina Bromatologia - Universidade Federal do Paraná - Campus Jardim \\ Botânico. Av. Lothário Meissner, 3400 - Jardim Botânico, CEP: 80210-170 - Curitiba, PR - Brasil. \\ bromatologia.ufpr@gmail.com \\ REC: 05/2010 AC: 06/210
}

\begin{abstract}
RESUMO:
O vinagre é um condimento obtido pelo processo de fermentação acética, que consiste na transformação do álcool em ácido acético, por determinadas bactérias. Tal bebida possui propriedades funcionais, tal como estimulante da digestão, anti-séptico, propriedade desinfetante, entre outros. Porém muitas vezes essas características são desconhecidas pela população, por se tratar de algo tão cotidiano e também pela falta de pesquisas realizadas sobre o tema. Os objetivos deste trabalho foram analisar as diversas variáveis que caracterizam os diferentes tipos de vinagres produzidos, compará-las com os dados da literatura e da legislação vigente pela Agência Nacional de Vigilância Sanitária (ANVISA) bem com o rótulo do produto. As variáveis analisadas foram: acidez total por cento, acidez volátil por cento, acidez fixa por cento, extrato seco e pH. Seguiram-se as metodologias oficias de análise propostas pelo Instituto Adolfo Lutz, versão eletrônica atualizada.
\end{abstract}

Palavras chaves: vinagre, fermentado acetico, controle de qualidade

\begin{abstract}
:
Vinegar is a condiment obtained from the process acetic fermentation that is the change of alcohol to acetic acid by some bacteria. This liquid has functional properties, like digestion stimulant, anti-septic, disinfectant, etc. Althoug, many characteristics are not known by the population, in the reason of being so usual and also for the lack of researches done about the theme. The objectives of this article were analyze the different variables that characterize the different vinegar and compare with the literature and with the legislation current by the Agência Nacional de Vigilância Sanitária (ANVISA) as well as the label of this product. The variables analyzed were: total acidity percent, volatile acidity percent, fixed acidity percent, dry extract and $\mathrm{pH}$. Were used the official methodologies of analysis proposal by the Institute Adolfo Lutz, electronic version updated.
\end{abstract}

Keywords: vinegar, fermented acetic, quality control

\section{INTRODUÇÃO}

A palavra vinagre derivada do idioma Francês vinaigre, que significa "vinho azedo", nada mais é do que o produto da transformação do álcool em ácido acético por bactérias acéticas. Juntamente com o vinho, foram os primeiros produtos de fermentação espontânea utilizados pelo homem na alimentação (EMBRAPA,2006). 
Embora o termo vinagre, isoladamente, corresponda ao produto obtido da acetificação do vinho, a matéria-prima utilizada para sua elaboração é variável em função da disponibilidade de cada país em que é fabricado, podendo partir do vinho, arroz, sidra, malte, álcool, entre outros (MARTINELLI FILHO, 1983; MORETO et al, 1988)).

O vinagre é considerado um condimento, pois a sua principal finalidade é atribuir gosto e aroma aos alimentos, também é utilizado para conservar vegetais e outras substâncias, atribuindo-Ihes gosto agradável (EMBRAPA,2006). Apresenta também utilidade como amaciante de carnes temperadas e legumes em conservas (BORTOLINI et al 2001).

Os condimentos, de modo geral, quando ingeridos em quantidades moderadas, estimulam a digestão. O vinagre apresenta propriedades estimulantes, pois favorece a secreção do suco gástrico aumentando a ação dissolvente (EMBRAPA,2006). Possui também ação de regulação da glicose sanguínea (EBIHARA; NAKAJIMA, 1988), controle da pressão arterial, estimulação do apetite e promoção da absorção de cálcio (XU; TAO; AO, 2007).

Além disso, é empregado como purificador de ar. Nesse sentido, foi utilizado no passado como desinfetante. Ele possui ação anti-séptica contra a cólera, Salmonella spp. e outros patógenos do intestino que causam infecções e epidemias, assegurando um ambiente ácido do suco gástrico que representa uma defesa contra as intoxicações microbianas que podem ocorrer. Por possuir propriedade desinfetante e antiinflamatória, foi utilizado na cura de feridas e úlceras (EMBRAPA,2006).

Do total de aproximadamente 170 milhões de litros de vinagre consumidos anualmente no Brasil, cerca de $80 \%$ são referentes ao vinagre de álcool. Depois do vinagre de álcool, o produto elaborado à base de vinho é o mais consumido no Brasil, seguido pelo vinagre balsâmico e pelos vinagres de frutas, principalmente maçã (ANAV,1999).

O vinagre é um produto de fácil acesso no Brasil, porém pouco valorizado comercialmente devido, em parte, ao desconhecimento do consumidor de suas propriedades funcionais. Isto é um reflexo do pequeno número de pesquisas realizadas no país sobre este tema (BELLINI, 2006).

\section{OBJETIVOS}

\subsection{Objetivo Geral}

Avaliaram-se se as características do vinagre comercializado na Região Metropolitana de Curitiba (RMC) no período de março a agosto de 2010 estão de acordo com a legislação vigente e dados obtidos da literatura.

\subsection{Objetivos Específicos}

Avaliaram-se diversas variáveis tais como:

- $\mathrm{pH}$;

- acidez total por cento;

- acidez fixa por cento;

- acidez volátil por cento; 
- extrato seco,

Estas variáveis foram comparadas com a legislação vigente na bibliografia e com as informações contidas no rótulo do produto.

\section{REVISÃO BIBLIOGRÁFICA}

\subsection{VINAGRE}

O vinagre é uma solução diluída de ácido acético, elaborada de dois processos consecutivos: a fermentação alcoólica, representada pela conversão de açúcar em etanol (álcool) e da fermentação acética, que corresponde à transformação do álcool em ácido acético por determinadas bactérias, conferindo o gosto característico de vinagre (MARQUES,2008).

Essas bactérias acéticas constituem um dos grupos de microrganismos de maior interesse econômico, de um lado pela sua função na produção do vinagre e, de outro, pelas alterações que provocam nos alimentos e bebidas.Pela classificação atual, as bactérias acéticas pertencem à família Pseudomonodaceae; aos gêneros Acetobacter e Gluconobacter. As principais espécies de bactérias acéticas são: Acetobacter aceti, Acetobacter pasteurianus, Acetobacter xylinum, Acetobacter schützenbachii e Gluconobacter oxydans (EMBRAPA,2006). A bactéria acética ideal é aquela que resiste à elevada concentração de álcool e de ácido acético, com pouca exigência nutritiva, elevada velocidade de transformação do álcool em ácido acético, bom rendimento de transformação, sem hiperoxidar o ácido acético formado, além de conferir boas características gustativas ao vinagre.

Existem fatores que podem interferir na fermentação acética de vinagres. Entre eles estão o $\mathrm{pH}$, a temperatura e aqueles pertinentes a microorganismos, como espécie, linhagem e concentração da levedura no meio (OLIVEIRA, 2006).

$O$ vinagre, assim como o vinho, está sujeito a alterações causadas principalmente pela falta de condições higiênicas adequadas durante o processo de elaboração.

As principais alterações que podem ocorrer no vinagre podem ser devido a "Anguilila" do vinagre (Anguillula aceti), pequeno nematóide, de $1 \mathrm{~mm}$ a $2 \mathrm{~mm}$ de comprimento que se desenvolve principalmente nos vinagres fracos, causando-lhes odores desagradáveis e aspecto indesejável, embora não seja prejudicial à saúde. A mosquinha do vinagre (Drosophylla melanogaster) é responsável pela transmissão de vários microrganismos infectantes desse tipo de condimento. Essas alterações também podem ser causadas por elementos químicos como ferro e o cobre que, quando em concentrações elevadas, causam escurecimento e turvação e transmitem um gosto metálico ao vinagre. Enfim, microorganismos diversos como várias espécies de bactérias, fungos e alguns ácaros, podem contaminar o vinagre, tornando-o, em casos extremos, impróprio para o consumo. Essas alterações causadas por microrganismos, podem ser evitadas através do controle rigoroso das condições de higiene no local de produção, enquanto que o cuidado de não deixar o vinagre em contato com recipientes e materiais de ferro e cobre diminui a concentração desses minerais (EMBRAPA,2006). 


\subsection{CLASSES DE VINAGRES}

Existem diferentes tipos de vinagres, que variam de acordo com o produto base de sua fermentação (BRASIL, 1999). Segue abaixo alguns exemplos:

- Vinagre de álcool: Obtido pela fermentação acética de uma mistura hidroalcoólica, originária do álcool etílico potável. Possui sabor mais acentuado, por ser originário de uma matéria-prima sem muitos nutrientes.

- Agrin branco ou Agrin tinto: É proveniente da fermentação acética de uma mistura hidroalcóolica originária do álcool etílico potável (90\%) e vinho branco ou vinho tinto (10\%). É denominado branco ou tinto de acordo com matéria prima utilizada.

- Vinagre de álcool claro ou vinagre de álcool escuro: É obtido pela fermentação acética de uma mistura hidroalcoólica, originária do álcool etílico potável.Assim como o Agrin, é classificado dependendo de sua coloração.

- Vinagre de vinho: É o vinagre proveniente da fermentação acética do vinho, podendo ele ser branco ou tinto. São vinagres mais puros, pois são elaborados com $100 \%$ do vinho, por este motivo carregam em sua composição os nutrientes do vinho e da uva.

- Vinagre de fruta: Proveniente da fermentação do suco de fruta como maçã, caqui, etc. São puros e carregam em sua composição os valores nutricionais das frutas de onde foram originados.

- Vinagre de cereais : No caso do vinagre proveniente do arroz, ele é $100 \%$ originário da fermentação desse cereal. Possui destaque na culinária oriental.

- Vinagre de mel: Obtido pela fermentação do mel de abelha. Utilizado para elaboração de doces e xaropes e como auxiliar em dietas nutricionais por conter os nutrientes do próprio mel.

A fabricação de vinagre proporciona um meio de utilização de matérias primas não aproveitáveis dos estabelecimentos industriais de frutas e especialmente de propriedades rurais que não poderiam competir no mercado (MARQUES, 2008)

\subsection{ESPECIFICAÇÕES DOS FERMENTADOS}

O fermentado acético de modo geral, é o produto obtido da fermentação acética do fermentado alcoólico de mosto de frutas, cereais ou de outros vegetais, de mel, ou da mistura de vegetais, ou ainda da mistura hidroalcoólíca, devendo apresentar acidez volátil mínima de 4,0 (quatro) gramas por 100 mililitros, expressa em ácido acético, podendo ser adicionado de vegetais, partes de vegetais ou extratos vegetais aromáticos ou de sucos, aromas naturais ou condimentos.

Porém, é designado de fermentado acético duplo, o vinagre que apresentar acidez volátil superior a 8 (oito) gramas de ácido acético por $100 \mathrm{~mL}$ do produto, e triplo o fermentado acético que apresentar acidez volátil superior a 12 (doze) gramas de ácido acético por $100 \mathrm{~mL}$ do produto.

Também é considerado fermentado acético misto aquele composto de fruta, cereal, mel ou vegetal e álcool, o fermentado que for adicionado de uma mistura hidroalcoólica em quantidade que corresponda no máximo a $50 \%$ da acidez final (BRASIL, 1999). 
TABELA 1: Padrão de acidez volátil de fermentados acéticos

\begin{tabular}{lccc}
\hline ACIDEZ VOLÁTIL EXPRESSA & $\begin{array}{c}\text { FERMENTADO } \\
\text { ACÉTICO }\end{array}$ & $\begin{array}{c}\text { FERMENTADO } \\
\text { ACÉTICO DUPLO }\end{array}$ & $\begin{array}{c}\text { FERMENTADO } \\
\text { ACÉTICO TRIPLO }\end{array}$ \\
\hline MÍNIMO & 4,0 & 8,0 & 12,0 \\
MÁXIMO & 7,9 & 11,9 & --- \\
\hline
\end{tabular}

Fonte: BRASIL, 1999.

Segundo a legislação (BRASIL, 1999) é proibida a elaboração de vinagres por diluição de ácido acético de origem não fermentativa. $O$ vinagre pode ser então classificado também como vinagre de vinho tinto ou de vinho branco, segundo a matéria prima utilizada. $O$ produto resultante da fermentação acética de outros produtos alcoólicos será denominado fermentado acético, podendo ser utilizado a palavra vinagre

\subsection{BENEFÍCIOS DOS VINAGRES}

O consumo de vinagre pode trazer inúmeros benefícios. De um modo geral, uma das características de todos os tipos de vinagre é o baixo valor calórico e também o fato de que pessoas hipertensas podem utilizá-lo como substituto do sal.

$O$ vinagre balsâmico tem propriedades estimulantes que colaboram com o processo de digestão.

Os vinagres feitos a partir da fermentação de frutas possuem características oxidantes, que retardam o envelhecimento. Como ocorre com o vinagre de maça, que além de possuir mais de trinta elementos nutritivos, mais de uma dúzia de sais minerais e enzimas essenciais, possui complexos multi-vitamínicos (EMBRAPA,2006).

Embora essas propriedades funcionais dos vinagres não estejam totalmente esclarecidas, propalam- se seu efeito positivo no controle do $\mathrm{pH}$ do estômago para combater a gastrite, no ataque aos radicais livres, evitando a manifestação de certos tipos de cânceres (NETO, 2006) e também na sua ação anti-séptica e antibiótica.

Uma pesquisa comprovou que o vinagre é eficaz para eliminar a larva do mosquito da dengue. A falta de seletividade no processo filtrante que as larvas possuem em sua alimentação e o fato do vinagre conferir ao ambiente aquático um caráter ácido, provocam no trato digestivo das larvas, danos irreparáveis e letais, levando-as a sua eliminação, independe dos estágios em que se encontram.

O pesquisador e engenheiro agrônomo Reinaldo José Rodella, em 2003, no município de Piracicaba, interior de São Paulo, realizou com a sua equipe, uma série de pesquisas utilizando o vinagre diluído na água, onde as larvas dos mosquitos estão depositadas. Os resultados indicaram que a partir de $5 \%$ de vinagre na água, todas as concentrações de ácido acético testadas foram letais para as larvas, constatando-se 
ainda um efeito residual de oito dias (ANAV,2010).

Basta uma colher de sopa de vinagre diluído na água e em cerca de três horas as larvas começam a ser eliminadas. A Associação Nacional das Indústrias de Vinagre informa que o uso do produto é uma das formas mais seguras e baratas para eliminar a dengue no Brasil, já que a sua ação é na larva do mosquito (ANAV,2010).

\section{MATERIAL E MÉTODOS}

No presente estudos, foram realizados experimento com o objetivo de confirmar se determinadas características dos vinagres utilizados, condiziam com o registrado pela legislação.

Os testes foram realizados com 10 amostras escolhidas de forma aleatória, de diferentes marcas e classes (álcool, maçã, limão, arroz ,etc.), comercializados em supermercados na da Região Metropolitana de Curitiba (RMC), no período de março a agosto de 2010.

As amostras coletadas foram testadas e estudadas no Laboratório de Bromatologia, no Departamento de Farmácia da Universidade Federal do Paraná.

Cada uma das 10 amostras foram devidamente conservadas em recipientes hermeticamente fechados e longe do abrigo de luz ou calor.

As amostras testadas e individualmente identificadas foram: Vinagre de álcool tipo escuro; Vinagre de álcool tipo escuro; Vinagre álcool com limão; Vinagre de álcool tipo claro; Vinagre de álcool com aroma de Hortelã; Vinagre de álcool tipo claro; Vinagre de maça, Vinagre de álcool com limão; Vinagre de álcool tipo claro; Vinagre de arroz.

Para avaliar as principais características dos vinagres, estabelecidas pela legislação, foram realizados os seguintes testes, seguindo as metodologias vigentes e descritas no IAL,2008:

A) VERIFICAÇÃO DE pH POR FITA UNIVERSAL

$\mathrm{O} \mathrm{pH}$ das amostras foi determinado utilizando a fita universal, que se baseia na mudança de coloração de acordo com a faixa de $\mathrm{pH}$ atingida.

B) VERIFICAÇÃO DE pH POR PHMETRO.

$\mathrm{O} \mathrm{pH}$ das amostras foi determinado pelo método de leitura direta por meio do aparelho digital

C) EXTRATO SECO

O extrato seco das amostras foi determinado por permanência das alíquotas em banho Maria, em estufa regulada a 105ํํ por 1 hora, seguida da pesagem das amostras até o peso constante.

D) ACIDEZ TOTAL

A acidez total é um experimento feito para encontrar o valor de ácido acético em g/100 mL ou $\mathrm{g} \%$ de vinagres. A acidez total dos mostos foi determinada pelo método da titulação volumétrica com solução de $\mathrm{NaOH} 0,1 \mathrm{~mol} L-1$, utilizando-se como indicador solução alcoólica de fenolftaleína a $1 \%$. 
E) ACIDEZ FIXA

Consta de um experimento semelhante a acidez total, porém antes de que a amostra seja submetida a uma titulação, ela deve estar em banho Maria até que seu conteúdo chegue próximo a secura.

F) ACIDEZ VOLÁTIL

A acidez volátil foi realizada por diferença entre acidez total e a acidez fixa.

\section{RESULTADOS E DISCUSSÃO}

\subsection{VERIFICAÇÃO DO pH}

Tanto a acidez quanto os valores de $\mathrm{pH}$ influenciam diretamente as características sensoriais dos vinagres (MARQUES, 2010).

$\mathrm{Na}$ tabela 2 encontram-se os resultados obtidos dos valores de $\mathrm{pH}$ para cada uma das variedades de fermentados acéticos estudados:

TABELA 2: Verificação do pH por fita universal e por pHmetro.

\begin{tabular}{lcc} 
AMOSTRAS DE VINAGRES & FITA UNIVERSAL & PHMETRO \\
\hline Vinagre de álcool tipo escuro & 2 & 2,44 \\
Vinagre de álcool tipo escuro & 2 & 2,42 \\
Vinagre álcool com limão & 2 & 2,52 \\
Vinagre de álcool tipo claro & 3 & 2,42 \\
Vinagre de álcool com aroma de hortelã & 2 & 2,44 \\
Vinagre de álcool tipo claro & 2,5 & 2,42 \\
Vinagre de maça & 3 & 2,64 \\
Vinagre de álcool com limão & 2 & 2,27 \\
Vinagre de álcool tipo claro & 3 & 2,39 \\
Vinagre de arroz & 3 & 2,84
\end{tabular}

A verificação do $\mathrm{pH}$ foi realizada por dois métodos distintos com o objetivo de compará-los na sua especificidade. Como se pode observar, o teste realizado com o pHmetro foi muito mais próximo a realidade em comparação com o realizado com a fita universal, que oferece um intervalo sem ser exato.

Pode-se perceber que o pH dos fermentados acéticos de álcool é mais baixo. 
Já o vinagre de maçã e o de arroz possuem um $\mathrm{pH}$ um pouco mais elevado, uma vez que ele é atenuado por substâncias orgânicas presentes nas respectivas matériasprimas (FLORENTINO, 2004).

Em vinagres com acidez em torno de $5 \%$, esperam-se intervalos de $\mathrm{pH}$ em torno de 2,46 a 3,18 , valores dependentes do tipo de vinagre a ser analisado, como vinagres provenientes de destilados, vinagres de vinho, vinagre de maçã, entre outros (WHITE, 1971). Sendo assim, as amostras testadas apresentaram valores bem próximos aos citados na bibliografia, uma vez que possuem valores de acidez volátil próximos a $5 \%$, que será observado mais para frente do estudo. Nenhuma das amostras possuía informações sobre $\mathrm{pH}$ em seu rótulo.

\subsection{ACIDEZ}

A acidez dos vinagres ocorre devido a presença do ácido acético e pode ser determinada através de titulações.

A acidez total do vinagre é expressa em ácido acético, principal ácido orgânico do vinagre, porém outros ácidos orgânicos estão presentes, dentre eles os principais são: tartárico, cítrico, málico, lático, succínico em vinagres de vinho $(\mathrm{COCCHI}$ et al, 2002, GEUM-SOON-OH et al, 2003, MORALES et al., 1998, RIZZON \& MIELE, 2001, SANARICO et al., 2003). Em vinagres de álcool o principal ácido é o ácido acético (AQUARONE \& ZANCANARO, 1990, NATERA et al., 2003).

A acidez total é o valor de ácido acético que existe na forma íntegra do vinagre. A acidez fixa, por sua vez, é realizada após evaporação de parte da amostra. Os valores de ambas as análises são expressos em g/100mL de ácido acético encontramse na tabela 3 .

TABELA 3: Acidez Fixa e Acidez Total.

\begin{tabular}{lcc}
\hline AMOSTRAS DE VINAGRES & Acidez fixa em g\% & Acidez total em $\mathbf{g} \%$ \\
\hline Vinagre de álcool tipo escuro & $1,42( \pm 0,006)$ & $8,95( \pm 0,001)$ \\
Vinagre de álcool tipo escuro & $1,68( \pm 0,002)$ & $8,35( \pm 0,09)$ \\
Vinagre álcool com limão & $1,82( \pm 0,019)$ & $8,17( \pm 0,06)$ \\
Vinagre de álcool tipo claro & $1,98( \pm 0,008)$ & $8,53( \pm 0,06)$ \\
Vinagre de álcool com aroma de & $3,51( \pm 0,004)$ & $7,93( \pm 0,06)$ \\
hortelã & & \\
Vinagre de álcool tipo claro & $2,07( \pm 0,015)$ & $8,65( \pm 0,001)$ \\
Vinagre de maça & $2,27( \pm 0,024)$ & $8,71( \pm 0,06)$ \\
Vinagre de álcool com limão & $3,55( \pm 0,005)$ & $11,04( \pm 0,001)$ \\
Vinagre de álcool tipo claro & $2,82( \pm 0,003)$ & $8,17( \pm 0,003)$ \\
Vinagre de arroz & $2,43( \pm 0,006)$ & $8,77( \pm 0,03)$ \\
\hline
\end{tabular}

A acidez volátil, entretanto, é a característica determinante de um fermentado acético. Segundo a legislação, devidos produtos devem conter um valor mínimo de 
4,0g/100 mL de ácido acético em sua composição (BRASIL, 1999), de forma que a difusão comercial e a aceitação dos produtos devem embasar-se no conhecimento de suas propriedades sensoriais, as quais contribuem para valorizar e proteger a genuidade dos mesmos (MARQUES, 2008). A tabela 4 contém os valores apresentados na rotulagem das devidas amostras de vinagre.

TABELA 4 : Acidez volátil declarada no rótulo pelo fabricante.

\begin{tabular}{lc}
\hline AMOSTRAS DE VINAGRES & $\begin{array}{c}\text { ACIDEZ VOLÁTIL DECLARADA } \\
\text { NO RÓTULO em g\% }\end{array}$ \\
\hline Vinagre de álcool tipo escuro & $4,2 \%$ \\
Vinagre de álcool tipo escuro & $4,2 \%$ \\
Vinagre álcool com limão & $3,0 \%$ \\
Vinagre de álcool tipo claro & $4,2 \%$ \\
Vinagre de álcool com aroma de hortelã & $4,0 \%$ \\
Vinagre de álcool tipo claro & $4,2 \%$ \\
Vinagre de maça & $4,2 \%$ \\
Vinagre de álcool com limão & $4,0 \%$ \\
Vinagre de álcool tipo claro & $4,2 \%$ \\
Vinagre de arroz & $4,15 \%$
\end{tabular}

A acidez volátil, expressa em g de ácido acético/100mL, é obtida através de diferença entre os valores das determinações das acidez total e da acidez fixa (Tabela 4). A Tabela 5 mostra os valores encontrados em acidez volátil das amostras.

TABELA 5: Acidez volátil encontrada segundo os testes.

\begin{tabular}{lc}
\hline AMOSTRAS DE VINAGRES & $\begin{array}{c}\text { MÉDIA ACIDEZ VOLÁTIL em } \\
\text { g/100mL de ác. acético com DP }\end{array}$ \\
\hline Vinagre de álcool tipo escuro & $7,53( \pm 0,023)$ \\
Vinagre de álcool tipo escuro & $6,67( \pm 0,015)$ \\
Vinagre álcool com limão & $6,35( \pm 0,035)$ \\
Vinagre de álcool tipo claro & $6,55( \pm 0,005)$ \\
Vinagre de álcool com aroma de hortelã & $4,42( \pm 0,060)$ \\
Vinagre de álcool tipo claro & $6,58( \pm 0,025)$ \\
Vinagre de maça & $6,44( \pm 0,009)$ \\
Vinagre de álcool com limão & $7,49( \pm 0,035)$ \\
Vinagre de álcool tipo claro & $5,35( \pm 0,060)$ \\
Vinagre de arroz & $6,34( \pm 0,015)$ \\
\hline
\end{tabular}


Segundo a comparação entre os dados fornecidos pelos fabricantes e os dados da tabela 3, nenhuma das amostras de fermentados acéticos obteve o teor de ácido acético conforme a rotulagem e sim muito mais elevado, chegando a ultrapassar $87 \%$ do valor em média para as amostras de vinagre de álcool tipo escuro e álcool com limão; 62\% para as amostras 2, 3, 4, 6, 7 e 10; 33\% para amostra 9. A amostra 5 vinagre de álcool com aroma de hortelã foi aquela que mais se aproximou do valor apresentado no rótulo, mesmo assim ultrapassou em 10\% o valor prescrito no rótulo.

Segundo as informações retiradas do regulamento técnico para fixação dos padrões de identidade e qualidade para fermentados acéticos do Ministério da Agricultura (BRASIL, 1999) apresentadas na tabela 1, podemos perceber que os vinagres testados durante o presente estudo, se enquadram na classificação de fermentados acético simples, com acidez volátil entre 4,0 e 7,9g/100 mL.

\subsection{EXTRATO SECO}

TABELA 6: Extrato seco.

\section{AMOSTRAS DE VINAGRES}

Vinagre de álcool tipo escuro

Vinagre de álcool tipo escuro

Vinagre álcool com limão

Vinagre de álcool tipo claro

Vinagre de álcool com aroma de hortelã

Vinagre de álcool tipo claro

Vinagre de maça

Vinagre de álcool com limão

Vinagre de álcool tipo claro

Vinagre de arroz

\section{EXTRATO SECO EM}

g/L com DP

$$
\begin{aligned}
& 1,83( \pm 0,0005) \\
& 1,88( \pm 0,0009) \\
& 3,36( \pm 0,0029) \\
& 1,49( \pm 0,0088) \\
& 1,57( \pm 0,0010) \\
& 1,19( \pm 0,0005) \\
& 6,31( \pm 0,0004) \\
& 5,04( \pm 0,0005) \\
& 1,38( \pm 0,0005) \\
& 7,46( \pm 0,0002)
\end{aligned}
$$

A legislação estipula valores quanto ao extrato seco, de acordo com as diferentes classes de vinagres. De acordo com o Ministério da Agricultura, fermentados acéticos de álcool devem possuir em torno de 1,0 g/L de extrato seco; por sua vez, os de frutas $6,0 \mathrm{~g} / \mathrm{L}$.

Sendo assim, segundo a tabela acima, os vinagres de álcool e de maçã estão de acordo com os parâmetros. Os vinagres de álcool com limão apresentam valores intermediários, uma vez que mesclam o álcool com a fruta. 


\section{CONCLUSÃO}

Após observar os resultados dos testes realizados nas amostras de vinagres, podemos concluir que atingimos os objetivos de comparar os valores obtidos experimentalmente com a literatura.

Através dos resultados de $\mathrm{pH}$ observamos que as amostras testadas apresentaram valores muito próximos aos estabelecidos pela literatura, assim como na avaliação do extrato seco, uma vez que os vinagres obtiveram valores dentro do esperado, cada um de acordo com a sua classe.

Em se tratando de acidez, a que é levada em consideração é a volátil, pois é aquela que classifica um fermentado e também a que é especificada em sua rotulagem. Todas as amostras obtiveram valores para serem classificadas como fermentado acético simples, como o esperado, apresentando valores de acidez volátil entre 4,0 e $7,9 \mathrm{~g} \%$ de ácido acético. Porém, os vinagres pesquisados, apresentaram esses valores muito acima do que foi especificado no rótulo.

Nenhuma das amostras apresentou nenhum sinal de alteração conforme a literatura.

\section{REFERÊNCIAS}

ANAV, Associação Nacional das Industrias de Vinagres. Disponível em: http://www. anav.com.br/clipping_interna.php?id=26 Acesso em: 26/06/2010.

AQUARONE, E.; ZANCANARO JR., O. Vinagres. In: AQUARONE, E.; LIMA, U. A.; BORZANI, W. (ed.). Alimentos e bebidas produzidos por fermentação. São Paulo: Edgard Blücher, 1990. p.105-123.

BELLINI, M. Z. Caracterização bioquímica dos vinagres brasileiros. 2006. 82f Tese Faculdade de Engenharia de Alimentos da UNICAMP. Campinas, 2006.

BORTOLINI, F.; SANT'ANNA, E. S.; TORRES, R. C. Comportamento das fermentações alcoólica e acética de sucos de kiwi (Actinida deliciosa): composição dos mostos e métodos de fermentação acética. Ciência e Tecnologia de Alimentos, v. 21, n. 2, p. 236-243, 2001.

BRASIL. Ministério da Agricultura, Pecuária e Abastecimento. Instrução Normativa $\mathrm{n}$. 36 , de 14 de outubro de 1999. Aprova o regulamento técnico para fixação dos padrões de identidade e qualidade para fermentados acéticos. Diário Oficial da União, Poder Executivo, Brasília, DF, 15 de outubro de 1999, Seção 1, p. 76.

COCCHI, M.; LAMBERTINI, P.; MANZINI, D.; MARCHETTI, A.; ULRICI, A. Determination of Carboxylic acids in vinegar and in Aceto Balsâmico Tradizionale di Modena 
by HPLC and GC methods. Journal of Agricultural and Food Chemistry, 2002; 50(19): 5255-5261.

EBIHARA, K.; NAKAJIMA, A. Effect of acetic acid and vinegar on blood glucose and insulin responses to orally administered sucrose and starch. Agricultural and Biological Chemistry, v. 52, n. 5, p. 1311-1312, 1988.

EMBRAPA, Sistema de Produção de Vinagres, 2006. Disponível em: http://sistemasdeproducao.cnptia.embrapa.br/FontesHTML/Vinagre/SistemaProducaoVinagre Acesso em: 18/07/2010.

FLORENTINO, E. R. Avaliação das principais características de vinagres comerciais. Higiene Alimentar. Paraíba- João Pessoa. v 18, nº 119. Abril, 2004.

GEUM-SOON-OH; KIL-JIN-KANG; YEONG-PYO-HONG; YEOUNG-SUN-AN; HYANG-MI-LEE. Distribuition of organic acids in trditional and modified fermented foods. Journal of the Korean Society of Food Science and Nutrition. 2003; 32(8): 1177-1185.

IAL - INSTITUTO ADOLFO LUTZ. Métodos Físico-Químicos para Análise de Alimentos - IV edição - Instituto Adolfo Lutz, Versão on line de 2008. Disponível em www. ial.sp.gov.br/index.php?option=\%20com_remository\&itemid id=0\&func=select\&orderby=1 acesso em março de 2010.

MARQUES,F. Características físico-químicas, nutricionais e sensoriais de vinagres de diferentes matérias primas.Dissertação de Mestrado, Curso de Engenharia de Alimentos. Universidade Federal de Goiás, 2008.

MARQUES, F., SPINOSA, W.,FERNANDES, K., CASTRO, C.,CALIARI, M. Padrões de identidade e qualidade de fermentados acéticos comerciais de frutas e vegetais. Ciência e Tecnologia de Alimentos. Campinas, 30(Supl.1): 119-126, maio 2010.

MARTINELLI FILHO, A. Tecnologia de vinhos e vinagres de frutas. Agroindústria de baixo investimento. Secretaria da Indústria, Comércio, Ciência e Tecnologia. Departamento de Tecnologia Rural da ESALQ/USP. 1983, 130p.

MORALES, M.L.; GONZALEZ G.A.; TRONCOSO, A.M., Íon-exclusion chromatographic determinaton of organic acids in vinegars. Journal of Chromatographic $\mathbf{A}$, 822, 1998, 45-51.

MORETTO, E.; ALVES, R.F.; CAMPOS, C.M.T.; ARCHER, R.M.B.; PRUDENCIO, A. Vinhos e vinagres: processamento e análises. Florianópolis: Ed. UFSC, 1988. $168 \mathrm{p}$.

NATERA, R.;CASTRO,R., GARCIA-MORENO,M.V.;HERNÁNDEZ, M.J,; GAR- 
CIABARROSO, C. Chemometric Studies of Vinegar from Different Raw Materials and Processes of Production. Journal of Agricultural and Food Chemistry 2003, 51, 33453351.

NETO, G.N. Vinagre brasileiro ainda está distante do padrão de qualidade internacional. Jornal da Unicamp. Universidade Estadual de Campinas, 2006.

OLIVEIRA, L. P. Seleção e aproveitamento biotecnológico de frutos encontrados na Amazônia para elaboração de bebidas alcoólicas fermentadas utilizando le-

vedura imobilizada. 2006. 177f. Tese- Universidade Federal do Amazonas. Amazonas, 2006.

RIZZON, L.A.; MIELE, A. Concentração de ácido tartárico dos vinhos da serra gaúcha. Cienc Rural vol 31 no 5 Santa Maria Sept/Oct. 2001.

SANARICO, D.; MOTTA, S.; BERTOLINI, L.; ANTONELLI, A. HPLC Determination of organic acids in Traditional Balsamic Vinegar of HPLC Determination of organic acids in Traditional Balsamic Vinegar of Reggio Emilia. Journal of Liquid Chromatography and Related Technologies. 2003; 26(13): 2177-2187.

TESSARO, D., LARSEN, A., DALAGO, R., DAMASCENO, S.,SENE, L., COELHO, S.Avaliação das fermentações alcoólica e acética para produção de vinagre a partir de suco de laranja. Acta Scientiarum. Technology. Maringá, v. 32, n. 2 p. 201-205, 2010.

WHITE, J. Vinegar quality: legal and commercial standards. Process Biochemistry, p. 21-25, 1971

XU, Q.; TAO, W.; AO, Z. Antioxidant activity of vinegar melanoidins. Food Chemistry,. 102, n. 3, p. 841-849, 2007. 